Lep. Rev. (1968) 39, 1, 45-49

\title{
A Survey of the Results of Residence in an Experimental Rehabilitation Unit for Leprosy Patients
}

*ERNEST P. FRITSCHI, м.B., D.oRTH., F.R.c.s.

Department of Orthopaedics

A. J. SELVAPANDIAN, B.sc., M.B., M.s., F.A.c.s. Head of the Department of Orthopaedics

Mns. SUSIE KOSHY

Honorary Superintendent, Nava Jeevana Nilayam

S. R. RADHAKRISHNAN, м.A.

Social Worker, Department of Orthopaedics

Christian Medical College and Hospital, Vellore, S. India

Deformity and the resulting disfigurement of the extremities and face is the main factor responsible for the difficulty in the rehabilitation of leprosy patients. Functional disability is also a factor, but one which is more easily overcome. Ever since surgical reconstruction of these deformities was developed by the pioneering work of Professor Brand in the Department of Reconstructive Surgery in Leprosy of the Christian Medical College and Hospital, Vellore, a new hope has been made available for such persons who were hitherto considered hopeless from the point of view of rehabilitation. Even though, however, a nearly normal function of hands and feet which were badly affected can now be restored, there remains the very serious hazard of residual anaesthesia. This shows itself to be a real problem when such patients are asked to perform any form of manual labour. Sixteen years ago, in Vellore, an experimental Rehabilitation Centre was established where young men between 15 and 25 years of age were admitted for varying periods to learn to use their hands and feet in doing a variety of jobs including carpentry, toy making and manufacture of articles from perspex, etc. To minimise the hazards of injury to the anaesthetic extremities, modifications were made to their tools.
A SURVEY OF THE RESUltS

In leprosy as in other conditions which give rise to disability, it is extremely important to prevent the patient from becoming dehabilitated and consequently care has been taken in the selection of patients for admission to the Rehabilitation Centre. Thecriterionforadmission has always been a degree of deformity which rendered the boy unable to gain admission to a regular school and also boys who have either been rejected from their home environment or otherwise unable to secure the means of livelihood. We would like to stress the great importance of not taking young people out of a normal school in order to train them in vocation. It is of extreme importance that as far as possible, any patient for whom there is normal provision in his home environment should remain in that environment.

The aim of the Centre has been two-fold, viz., to teach the patient the use of his hands and feet without the danger of injury and further deformity and to teach him a trade or skill with which he can earn a living. Great stress has been laid upon the practising of exercises to prevent

* Present address: Deputy Superintendent \& Surgeon, The Leprosy Mission, Vadathorasalur, Tiyagadrug P.O., S. Arcot District, Madras. 
contracture and the daily inspection of hands and feet to detect early signs of injury or infection and the importance of reporting immediately any injury sustained. In this way, a new "Reflex of caution" is initiated so as to replace the loss of the protective reflexes initiated in normal individuals by the sensation of pain.

In the selection of suitable vocations for patients with anaesthetic extremities it was recognised that the normal mechanisms of protection are two-fold. One is by the conscious knowledge of impending danger, and the other by the possession of the faculty of pain. For example, in the use of a sharp instrument a normal person does not rely on his sense of pain to inform him of the danger of the instrument. He relies on his knowledge that the instrument is sharp and must therefore be handled with caution. This knowledge is common knowledge to everybody. On the other hand, in the matter of handling hot objects the information obtained from the sensory nerve endings on the part of the body in contact with the object is the information upon which the reflex withdrawal is effected. If the sensory nerve endings are defunct this information is lacking and burns are sustained. Similarly in the production of blisters due to handling tools in the performance of heavy work, the normal individual relies on the sense of soreness which precedes the onset of the blister. If this soreness is absent the blister forms unknown to the patient. Thus, the choice of a trade suitable for leprosy patients should involve, as far as possible, the avoidance of processes involving heat and the use of protective devices and modifications of tools to prevent friction blisters. The type of skills introduced in the Centre, therefore, were:-

1. Carpentry.

2. Toy making.

3. Manufacture of articles from perspex. In addition to these, small scale kitchen gardening and poultry keeping were also taught. All the boys attend evening school so that the emphasis on reading and writing has been maintained.
The Centre consists of thatched houses with brick and mud plaster walls, white-washed and provided with adequate ventilation. The object of this is to avoid divorcing the patients from their normal village environment as much as possible. The workshop equipment was such as to involve the minimum use of power-driven tools although in later years it has become recognised that the almost universal availability of electricity has made the use of power less undesirable than it was 15 years ago.

During their stay in the Centre the boys are taught their trade and financial credit is given to them as soon as they are able to produce marketable goods. This credit is allowed to accumulate in their names and they are only issued pocket money as required. The total accumulated saving is given to the patient on discharge from the Centre either in the form of cash or in the form of a set of tools to serve as a means of continued productivity.

DISCUSSION OF FINDINGS

It will be noted (Table 1 ) that the percentage of follow-up obtained was 74.6. In every follow-up analysis of leprosy patients that we have so far conducted we have experienced great difficulty in contacting the patients after discharge and this figure is exceptionally good.

TABLE I

\begin{tabular}{lccc}
\hline & & Total & Follow-up \\
\hline No. of persons interviewed & $\ldots$ & 30 & 30 \\
No. of persons circularised & $\ldots$ & 45 & \\
No. of replies received & $\ldots$ & & 26 \\
\cline { 2 - 4 } Total numbers contacted & $\ldots$ & 75 & 56 \\
\cline { 2 - 3 } & & & \\
Percentage of follow-up: $74.6 \%$ & &
\end{tabular}

Of the 56 patients who were followed-up 1:3 patients were found to be unemployed $(23 \%)$ (Table $2 \mathrm{a})$. This figure was rather higher than we had expected. In some of these cases the family circumstances were sufficiently satisfactory so that the line of least resistance was depending upon the family. Two members were definitely known to have resorted to begging. The entire pattern of public opinion which we 
attempt to inculcate in the Rehabilitation Centre is that begging is the worst possible mode of existence and therefore it was disappointing to find that even as small a number as 2 had resorted to this. These 2 boys were without any family and presumably were driven to this plight out of desperation. Subsequently one of these 2 was re-admitted for treatment of ulcers and is now working on a piece-work basis in the Splint Workshop attached to the Christian Medical College Hospital. Of the employed group, the large figure of 31 out of $56(55.4 \%)$ were working under conditions which must be called protected industry, since all the institutions in which they are working are specifically intended for disabled persons (Table 2b).

TABLE 2a

Self-employed: Agricultural labourers .. 5

$\begin{array}{llll}\text { Artisans ... } & \ldots & \ldots & 2\end{array}$

Employed in Institutions

Partial Employment: Artisans .

Unemployed (dependent on others)

TABLE $2 \mathrm{~b}$

Swedish Red Cross Rehabilitation Industries . Government and Private Institutions ... . . Hind Kusht Nivaran Sangh Socks Factory,

$\begin{array}{lllllll}\text { Seplanatham } & \ldots & \ldots & \ldots & \ldots & \ldots\end{array}$

C.M.C. Hospital

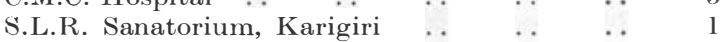

$\begin{array}{llllll}\text { Other Leprosy Institutions } & \ldots & \ldots & \ldots & 5\end{array}$

The difficulty which these boys have evidently experienced in securing self-employment is a factor to be noted. The design of the vocations taught was such as to enable patients to be self-employed (Table 3).

TABLE: 3

$\begin{array}{lr}\text { Carpentry . . } & 18 \\ \text { Toy Making } & 26 \\ \text { Kitchen Gardening } & 2 \\ \text { Poultry Keeping } & 2 \\ \text { Miscellaneous } & 8\end{array}$

'This aim has evidently not been achieved, and resort has, in many instances, been made to employment in a protected industry. It cannot be said that the teaching of carpentry was a total mistake since the skills that they learned in carpentry are being made use of to a very large extent by the individuals in the carrying out of their duties in the protected industries in which they are now employed. Furthermore, we can presume, although it is statistically impossible to substantiate this presumption, that this experience taught them to use tools and instruments with the least possible damage to their anaesthetic extremities. It is felt that the failure of the self-employment ideal may be related to the fact that in India the social structure is very conservative and trades tend to run in families and in communities and outside intrusion into these trades is resented by society.

TABLE 4

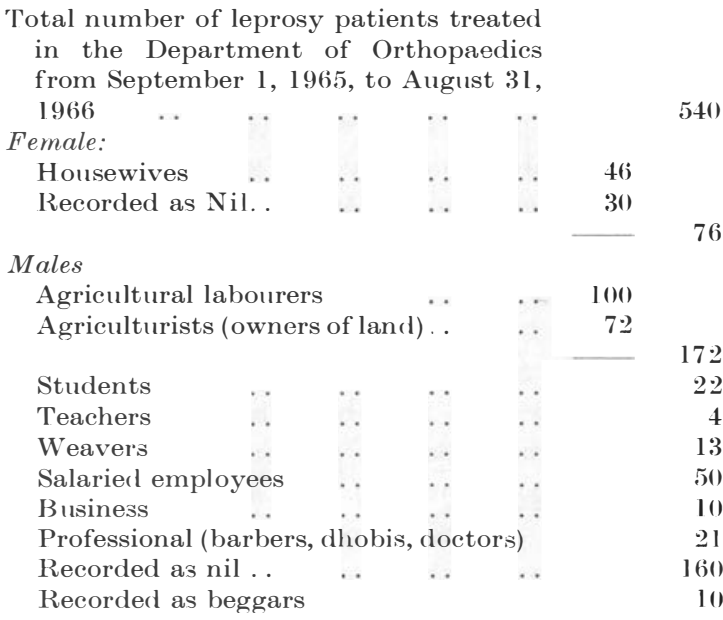

An analysis of the occupation of the outpatients for one year (Table 4) revealed that most of our patients who form the reservoir from which the Rehabilitation Centre members are drawn were agricultural labourers. It would seem therefore important that the vocation taught must be related to the background from which the patients have come. If a person belongs to a weaving community he 
should be taught weaving. Similarly, if he comes from an agricultural community his vocational training should be in terms of agriculture. In conversation with some of these patients who were interviewed we found that a number of them had sold the tools with which they were equipped on leaving the Centre. In many cases this was done only after obtaining reasonably secure employment which did not involve the use of these tools.

TABLE 5

Marital Status of Ex-Members

\section{Single}

Happily married

Married and separated

Widowed . .

A study of the marital status (Table 5) showed that only a small percentage were now living normal married lives. It is our belief that family life is an essential part of rehabilitation. Hence this subject was also investigated. Twelve members got married after leaving the Rehabilitation Centre. Forty-three members are living alone. Three members have married expatients and the remaining 10 have married women who have never had leprosy. Ten out of 12 married couples are living together happily. Out of these one member has concealed his previous disease from his wife and the remaining 2 are living separately on account of this disease. Out of these married couples 7 have children. The fact that successful family life has been so far denied to 45 out of 56 ex-members must remain a matter for some concern.

An attempt was made to relate the duration of stay in the Rehabilitation Centre with the ultimate rehabilitation of the patients but it was found that this did not correlate at all. To some extent this is understandable because people who stayed the longest in the Rehabilitation Centre were often those who constituted the biggest problem in job placement.

\section{CONCLUSIONS}

1. The teaching of a vocation which involves a deviation from the traditional employment of a person is probably not advisable except if the person is being taught with a view to absorption in some protected industry.

2. Self-employment of patients which is the obvious ideal, in order to be successful, must involve the return of the patient to his home environment and the pursuit of the occupation in which his family is concerned. If, for example, instead of equipping a person who comes from an agricultural background with a set of carpentry tools he is given a yoke of oxen it would be possible for him to earn Rs. 3/- per day in hiring the services of himself and his oxen to the local villagers. This has been proved experimentally in an agricultural programme upon which we have now embarked in the Rehabiliation Centre since the commencement of this study. We find that the demand for our oxen and plough in the local villages is very high and there has been no difficulty at all in the villagers accepting our patients irrespective of their deformity, if they are able to assist in ploughing the fields.

3. Poultry keeping and kitchen gardening are examples of trades which can only be carried out if a small quantity of land is available for the person and if such land is not available it is not possible for them to carry out these vocations.

How then should rehabilitation be planned in a country such as India? It is felt strongly that protected industry must feature largely in any rehabilitation programme since many of the patients are already displaced persons and not acceptable in their own community. Furthermore, most of them are landless and are therefore unable to practice kitchen gardening and poultry keeping.

In past years the idea of settling patients in small communities on pieces of land has been frowned upon. It has been stated that it is most undesirable to create 'leprosy villages'. We, however, differ from that view. We feel that small co-operative farming communities must be set up, the land being obtained from the 
District Collector, and assistance given to the group to start agriculture and to supplement the income from the agriculture by small cottage industry and live stock. The advantages of this system are that the patients working together have no difficulty in producing the goods. They must be responsible mutually for the care of any of their members who are temporarily incapacitated by injury or foot ulceration. Permanent incapacitation will, of course, involve institutional care. They can be provided corporately with improved agricultural instruments such as a power tiller and a pump in the well which will enable them to cultivate the fields economically with the least possible injury to themselves. They will have a sense of independence and will probably be able to marry and start families. The children of these small communities can easily be kept under regular medical surveillance and prophylactic DDS. They must attend the local village school. This, in our experience, is not difficult because so far we have not encountered any prejudice against children who have no deformity going to schools. It is deformity that society fears and if this is absent society can easily be educated to accept these children. In the course of one generation the village will cease to carry the stigma which in the present generation they may be likely to bear. It appears to us that the advantages of this pattern far outweigh the theoretical disadvantages of the stigma persisting.

The problem of leprosy is not a small problem. In the area in which we are working the incidence is between 2 and $3 \%$ of the total population. The schemes that we envisage involve fairly large outlays of capital and allocations of land. We believe that it is necessary that such outlay and allocations be made. If the problem of the elimination of the leprosy beggar is to be taken seriously it is necessary that a patient be prevented from becoming a beggar. The only way that this can be accomplished is by a concerted effort being made, assisted by Government co-operation, to provide for displaced persons who would otherwise have to resort sooner or later to begging. It is our conviction, based on the work that these boys have showed themselves capable of turning out, that such small agricultural communities and protected industries can be as productive as any local village community. If the small communities are taught to take advantage of the assistance now available in the form of improved agricultural methods, improved seed and scientifically controlled fertilising we believe that their rate of productivity will be higher than that of the average village community, in spite of the hazards of ulcers and injury which leprosy brings in its wake.

Believing this we look forward with faith to the time when the disabled, from whatever cause, will no longer be dependent on the community but will bear their own burden of responsibility and share in the mutual interdependence which must characterise any eulightened and democratic society. 